\title{
Comparison of Machine Learning Analysis on Predictive Factors of Children's Planning-Organizing Executive Function by Income Level: Through Home Environment Quality and Wealth Factors
}

\author{
Hye-Kyung Lim ${ }^{1}$, Hyun-Ok Kim²*, and Hae-Seon Park ${ }^{3}$ \\ ${ }^{1}$ Lecturer, Dept. of Social Welfare, Gyeongsang National University, Jinju-si Gyeongsangnam-do 52849, Republic of Korea \\ ${ }^{2}$ Professor, Dept. of Social Welfare, Gyeongsang National University, Jinju-si Gyeongsangnam-do 52849, Republic of Korea \\ ${ }^{3}$ Research Fellow, Institute of Social Welfare, Gyeongsang National University, Jinju-si Gyeongsangnam-do 52849, Republic of Korea
}

\section{ABSTRACT}

Background and objective: This study identifies whether children's planning-organizing executive function can be significantly classified and predicted by home environment quality and wealth factors.

Methods: For empirical analysis, we used the data collected from the 10th Panel Study on Korean Children in 2017. Using machine learning tools such as support vector machine (SVM) and random forest (RF), we evaluated the accuracy of the model in which home environment factors classify and predict children's planning-organizing executive functions, and extract the relative importance of variables that determine these executive functions by income group.

Results: First, SVM analysis shows that home environment quality and wealth factors show high accuracy in classification and prediction in all three groups. Second, RF analysis shows that estate had the highest predictive power in the high-income group, followed by income, asset, learning, reinforcement, and emotional environment. In the middleincome group, emotional environment showed the highest score, followed by estate, asset, reinforcement, and income. In the low-income group, estate showed the highest score, followed by income, asset, learning, reinforcement, and emotional environment.

Conclusion: This study confirmed that home environment quality and wealth factors are significant factors in predicting children's planning-organizing executive functions.

Keywords: executive function, income group, random forest (RF) analysis, support vector machine (SVM) analysis, home environment quality

\section{Introduction}

Executive function is known to be an important area of development to understand children's learning process as well as a predictor variable that has a great impact on school adjustment and scholastic achievement (Barkley, 1997; Espy et al., 2004; Graziano et al., 2007; Blair and Razza, 2007; Song, 2011). In particular, planning-organizing executive functions refer to the ability to systemize the hypothesis, set a goal, and concretize the methods and procedures
(Carlson et al., 2004; Welsh and Huizinga, 2005), which have a critical impact on children's academic achievement (Duncan et al., 2017; Kim et al., 2020). In fact, children who faced more difficulties in the planning-organizing process had lower IQ (intelligence quotient) and linguistic understanding (Song, 2014). It was generally known that children's executive functions are human traits that are formed relatively earlier in life. However, recent neuroimaging studies have proved that children's brain development is closely related to environmental factors such as the socioeconomic

Received: August 3, 2021, Revised: September 13, 2021, Accepted: November 23, 2021

First author: Hye-Kyung Lim, lhk_23@hanmail.net, (10) https://orcid.org/0000-0002-6120-0888

*Corresponding author: Hyun-Ok Kim, hyunj@gnu.ac.kr, (1) https://orcid.org/0000-0001-7475-409X 
status of their parents (Noble et al., 2012; Brito and Noble, 2014). More specifically, the brain structure of children living in poverty showed a relatively smaller area of the cerebral cortex than children from wealthy families, proving that the low income of parents had a negative effect on children's intellectual development (Noble et al., 2015). This shows that socioeconomic status or family wealth is closely related to children's executive function (Lawson et al., 2017; Kim and Pak, 2018).

According to studies on brain structure, executive functions of humans are intellectual skills such as cognitive, emotional, and behavioral regulation (Diamond, 2013; Diamond and Ling, 2016) that are connected to two parts of the brain (Poland et al., 2016). In other words, the dorsolateral prefrontal cortex is in charge of the cognitive process for reasoning and solving problems, while the orbitofrontal cortex is in charge of the emotional process like making decisions related to emotions, aggression, and emotional empathy (Lee et al., 2007). In particular, the dorsolateral prefrontal cortex is in charge of developing planning-organizing executive functions, and in fact, insignificant or poor quality of linguistic stimuli at home deteriorate the development of language-supporting cortical regions in the left brain (Kuhl, 2007; Brito and Noble, 2014). Furthermore, families with low socioeconomic status consistently showed low executive functions of children (Noble et al., 2005; St. John et al., 2019). Proving that there is a correlation between socioeconomic status and the change in children's brain structure, it can also be discovered that there are not only genetic but also environmental factors in the intellectual development of humans. Therefore, it is necessary to analyze the environmental factors that have a negative effect on children's intellectual development based on socioeconomic inequality.

Meanwhile, the environment that affects children's intellectual skills has been long discussed with focus on physical elements of visible space (Marcineková et al., 2020). However, the environment that affects human growth and development include psychological and emotional elements based on care and communication, interacting with physical elements (Sohn et al., 2019). In particular, home environment for children must include not only physical elements or spatial quality of the house but also invisible elements such as interactions among family members (Xiaoli et al., 2021). This is because planning-organizing executive functions, which are children's typical intellectual skills, are formed and developed by constant stimuli of visible and invisible environments (Bush et al., 2000). This home environment must be covered as a key variable that classifies and predicts children's planning-organizing executive functions, and the relevance between home environment that includes wealth factors and children's intellectual skills must also be studied.

In particular, many risk factors are likely to be inherent in the environment faced by children living in poverty (Jang and Kim, 2014). In fact, in addition to creating an environment that supports learning and providing an opportunity to expand the vision, the spatial environment of home that can safely reveal curiosity also affects difficulty in executive functions (Yi and Jun, 2019). Moreover, poverty is childhood may lead to psychological and emotional deprivation due to lack of family interest and discipline beyond material deprivation (Lee et al., 2009). In addition, since many risk factors in poverty are combined and synergized (Gassman-Pines and Yoshikawa, 2006; Evans and Kim, 2007), children living in poverty are facing more disadvantages in terms of intellectual development (Kishiyama et al., 2009). Physical factors such as poor, below-par housing as well as psychological anxiety factors such as being away from an adult's protection tended to hinder children's self-regulation skills to cope with external demands (Evans and Kim, 2012). Meanwhile, children with positive and open communication with their parents and greater satisfaction with parent-child relationships showed greater school adaptability (Tesser et al., 1989; Lee and Lee, 2004). We can predict from this fact that home environment quality is an important factor that affects children's planning-organizing executive functions. Therefore, inequality in environmental factors including income to classify and predict planning-organizing executive functions leads to inequality in children's scholastic achievement.

Recently, the Korean society is facing economic polarization with limited access to education, which also restricts social mobility. As of 2018, persistence of social class in Korea was highest among OECD nations, which reflects this reality (OECD, 2018). This indicates that the economic 
status of parents is highly likely to be passed down to their children. In fact, family wealth has a significant impact on children's learning ability and educational achievement (Brooks-Gunn and Duncan, 1997; Mayer, 2002; Eamon, 2002; Kim and Lee, 2007; Kim et al., 2020). The gap in learning ability among children as an effect of family wealth may serve as a factor that expresses the gap in future socioeconomic status. Considering this, it is necessary to check whether children's planning-organizing executive functions can be predicted in each income group based on family wealth factors. Using this as an index, we can identify groups facing difficulties in educational achievement, derive their vulnerabilities, and find a turning point to reduce education gap caused by inequality.

Variables that predict children's intellectual development or educational achievement thus far were mostly focused on earned income of parents, with insufficient discussion on real estate or financial assets. Considering the case in Korea in which real estate accounts for $76 \%$ of total assets of economically active households, setting the economic level only based on earned income has limitations as it fails to properly consider the current situation (Kim et al., 2020).

Moreover, studies predicting children's planning-organizing executive functions are mostly focused on estimating the causal relations based on regression analysis on children's executive function and predictor variables. However, as previously examined, development of children's planning-organizing executive functions is complexly associated with not only socioeconomic factors but also home environment factors, which is why it is necessary to comprehensively analyze these factors and examine the difference by income group. Therefore, this study will examine home environment quality and wealth factors that affect children's planning-organizing executive functions by income group using machine learning techniques such as random forest and support vector machine with high reliability in predictive power and analyze the relative importance of these predictor variables. Random forest was used in this study as prediction results can be obtained by considering the interactions among various predictor variables as well as nonlinearity (Choi and Min, 2018). Moreover, the support vector machine has the benefit of not affected much by noises in data and not overfitted. In this study, even though real estate, earned income, and financial assets are variables with different units or periods of income generation, they are not affected even when used as independent variables (Kim et al., 2020).

Accordingly, this study will analyze whether home environment quality and wealth factors can significantly classify and predict children's planning-organizing executive functions by income group. Specific research questions are as follows.

Research question 1: What is the accuracy of the model that classifies and predicts children's planning-organizing executive functions by income group using home environment quality and wealth factors?

Research question 2: What is the importance of home environment quality and wealth factors that classify and predict children's planning-organizing executive functions by income group?

\section{Research Methods}

\section{Subjects}

This study was conducted using the 2017 data from the 10th Panel Study on Korean Children, and the subjects are children of 1,484 mothers in 2017. There were 757 boys and 727 girls, and their average age at the point of the survey was 112.6 months (9.38 years). Non-responses including outliers of respondents among this panel data were treated as missing values, and all cases with 1 or more missing values were excluded from analysis. As a result, we analyzed 663 cases.

\section{Measurement tools}

\section{Planning-organizing executive functions (exf)}

To evaluate planning-organizing executive functions, which are the intellectual and cognitive skills among children's executive functions, we used 11 items on 'difficulties in planning-organizing executive functions' out of children's executive function scale developed by Song (2014). In the Panel Study on Korean Children, higher scores indicated lower executive functions to assess the dif- 
ficulty, but this study used reverse operation so that higher scores indicated higher executive functions. The reliability was $\alpha=.89$.

\section{Earned income (income)}

Average monthly household income

\section{Financial assets (asset)}

Total financial assets of the year, such as deposits, insurance, stocks, bonds, funds not received, money lent, rents/leases

\section{Real estate (estate)}

Current values of houses, buildings, forests and fields, land, etc.

\section{Reactivity (reactivity)}

It is comprised of 10 items on parents' emotional and verbal reactivity to children and compassionate relationship, and the reliability was $\alpha=.91$.

\section{Encouragement of maturity (mature)}

It is comprised of 7 items on parents' expectations for children's mature and responsible behavior and sharing of rules within the family, and the reliability was $\alpha=.90$.

\section{Emotional environment (emotional)}

It is comprised of 8 items on how much parents can accept children's negative expressions, and the reliability was $\alpha=.88$.

\section{Learning materials and opportunities (learning)}

It is comprised of 8 items on creating an environment that supports learning and providing an opportunity to expand the vision, as well as parents' enthusiasm for learning, and the reliability was $\alpha=.92$.

\section{Reinforcement (reinforcement)}

It is comprised of 8 items on conscious use of family/community resources for children's development, and the reliability was $\alpha=.88$.

\section{Family community (community)}

It is comprised of 6 items on participating in activities that provide mutual joy and companionship among family members, and the reliability was $\alpha=.90$.

\section{Family bond (bond)}

It is comprised of 4 items on whether the father (or father figure) can meet children's demands when needed, and the reliability was $\alpha=.92$.

\section{Spatial environment (spatial)}

It is comprised of 8 items on the suitability of the spatial environment such as whether the house and surrounding are safe and interesting and whether there is enough space, and the reliability was $\alpha=.87$.

\section{Methods and tools of analysis}

To compare machine learning analysis on predictors of children's planning-organizing executive functions by income group using home environment quality and wealth factors, we first used the support vector machine (SVM). This is one of the machine learning tools to find a hyperplane on high or infinite dimensional space, perform classification or regression, and present predictive values $(\mathrm{Na}$, 2017). Moreover, SVM is also used as a method to classify the objects by maximizing the hyperplane using linear regression equations when classifying data that belong to different categories to solve the classification problems $(\mathrm{Na}$, 2017). It is used in various fields due to its high predictive power, and it has the benefit of not being overfitted or affected much by data noise. In this study, even though family wealth and home environment factors are variables with different units or periods of income generation, they are not affected by use as independent variables.

Second, random forest (RF) to assess the importance of predictor variables is a method that added the random process to bagging (bootstrap aggregating) ( $\mathrm{Na}, 2017$ ). Predictor variables are randomly extracted while forming the tree for each bootstrap sample, and the extracted variables are optimally divided, thereby analyzing the im- 
portance of variables used. It also has high predictive power and is relatively insensitive to outliers, and thus stable in conversion of independent variables and frequently used in analyzing the importance of variables. The statistics presented as a result of RF analysis is mean decrease Gini (MDG) that is the decrease of prediction uncertainty, with higher values indicating that high uncertainty is eliminated.

Third, this study used jamovi and R (ver. 3.6.1) / R-studio as analytical tools. For SVM analysis, we used svm() and predict() functions of 'e1071' package. To analyze the importance of RF variables, we used randomForest(), plot(), importance(), and varImpPlot() functions of 'randomForest' package.

\section{Results and Discussion}

\section{Descriptive statistics of subjects and variables}

\section{Child classification standard for income level and planning-organizing executive functions}

Income is divided into three levels, and the three wealth factors were converted to standard value and added up (property), dividing them into three levels: minimum $33.33 \%, 33.33 \%$ - 66.66\%, 66.66 - maximum. The low-income level is 1 , middle-income level is 2, and high-income level is 3. Statistics of wealth factors and planning-organizing executive functions in each level are as shown in Table 1.

\section{Comparison of variables by income group}

Table 2 shows the differences in variables by group. More specifically, there were significant differences in children's planning-organizing executive functions (exf), home environment의 encouragement of maturity (mature) · emotional environment (emotional) - learning materials and opportunities (learning) · reinforcement (reinforcement) · family community (community) $\cdot$ spatial environment (spatial), and three wealth factors.

\section{Machine learning analysis on prediction of children's planning-organizing executive functions by income level}

\section{Analysis on prediction of planning-organizing executive functions of children from low-income families}

Table 3 and Fig. 1 shows the results of analyzing MDG in the RF to predict planning-organizing executive functions of children from low-income families. More specifically, estate showed the highest score, followed by income, asset, reinforcement, emotional, and community.

\section{Analysis on prediction of planning-organizing executive functions of children from middle-income families}

Table 4 and Fig. 2 shows the results of analyzing MDG in the RF to predict planning-organizing executive functions of children from middle-income families. More specifically, emotional showed the highest score, followed by estate, asset, reinforcement, and income.

\section{Analysis on prediction of planning-organizing executive functions of children from high-income families}

Table 5 and Fig. 3 shows the results of analyzing MDG in the RF to predict planning-organizing executive functions of children from high-income families. More specifically, estate showed the highest score, followed by income, asset,

Table 1. Descriptive statistics of subjects surveyed and research variables

\begin{tabular}{|c|c|c|c|c|c|c|c|c|}
\hline & $\begin{array}{c}\text { estate } \\
\left(10^{4} \text { won }\right)\end{array}$ & $\begin{array}{c}\text { asset } \\
\text { (10 } 10^{4} \text { won) }\end{array}$ & $\begin{array}{l}\text { income } \\
\text { (10 } 10^{4} \text { won) }\end{array}$ & zestate & zasset & zincome & property & $x f$ \\
\hline $\mathrm{N}$ & 663 & 663 & 663 & 663 & 663 & 663 & 663 & 663 \\
\hline Minimum & 500 & 30 & 90 & -0.346 & -0.678 & -0.935 & -1.75 & 1 \\
\hline Maximum & $3,300,000$ & 100,000 & 8,500 & 32.9 & 8.05 & 16.5 & 12.9 & 5.8 \\
\hline 33.33th & 20,000 & 2,000 & 400 & -0.15 & -0.506 & -0.294 & -0.731 & 1.4 \\
\hline 66.67 th & 32,000 & 6,000 & 550 & -0.0288 & -0.157 & 0.0169 & -0.00733 & 1.8 \\
\hline
\end{tabular}


Table 2. Validate differences in study variables by income group

\begin{tabular}{|c|c|c|c|c|c|}
\hline & property & $\mathrm{N}$ & Mean & SD & $\mathrm{F}$ \\
\hline & 1 & 221 & 1.63 & 0.4338 & \\
\hline exf & 2 & 221 & 1.65 & 0.5322 & $2.6684^{+}$ \\
\hline \multirow{3}{*}{ reactivity } & 1 & 221 & 1.04 & 0.0763 & \\
\hline & 2 & 221 & 1.04 & 0.0765 & $0.8685^{\mathrm{NS}}$ \\
\hline & 3 & 221 & 1.03 & 0.0658 & \\
\hline \multirow{3}{*}{ mature } & 1 & 221 & 1.07 & 0.1238 & \\
\hline & 2 & 221 & 1.08 & 0.1245 & $7.5466^{* * *}$ \\
\hline & 3 & 221 & 1.04 & 0.0837 & \\
\hline \multirow{3}{*}{ emotional } & 1 & 221 & 1.22 & 0.1870 & \\
\hline & 2 & 221 & 1.24 & 0.1686 & $2.8357^{+}$ \\
\hline & 3 & 221 & 1.21 & 0.1677 & \\
\hline \multirow[t]{2}{*}{ learning } & 2 & 221 & 1.34 & 0.1585 & $4.9401^{* *}$ \\
\hline & 3 & 221 & 1.3 & 0.1591 & \\
\hline \multirow{3}{*}{ reinforcement } & 1 & 221 & 1.27 & 0.2119 & \\
\hline & 2 & 221 & 1.23 & 0.2117 & $7.4868^{* * *}$ \\
\hline & 3 & 221 & 1.19 & 0.1934 & \\
\hline \multirow{3}{*}{ community } & 1 & 221 & 1.21 & 0.2051 & \\
\hline & 2 & 221 & 1.2 & 0.1972 & $3.2283^{*}$ \\
\hline & 3 & 221 & 1.17 & 0.1853 & \\
\hline \multirow{3}{*}{ bond } & 1 & 221 & 1.09 & 0.1961 & \\
\hline & 2 & 221 & 1.09 & 0.1716 & $0.0619^{\mathrm{NS}}$ \\
\hline & 3 & 221 & 1.09 & 0.1781 & \\
\hline \multirow{2}{*}{ spatial } & 1 & 221 & 1.11 & 0.1681 & \\
\hline & 3 & 221 & 1.07 & 0.1069 & \\
\hline \multirow{3}{*}{ estate } & 1 & 221 & 20333.48 & 11978.2667 & \\
\hline & 2 & 221 & 29080.09 & 15752.3407 & $44.7768^{* * *}$ \\
\hline & 3 & 221 & 48814.03 & 54251.8457 & \\
\hline \multirow{3}{*}{ asset } & 1 & 221 & 2138.89 & 1746.7646 & \\
\hline & 2 & 221 & 4214.16 & 2970.6707 & $122.1278^{* * *}$ \\
\hline & 3 & 221 & 16194.12 & 15597.8557 & \\
\hline \multirow{3}{*}{ income } & 1 & 221 & 351.24 & 111.6173 & \\
\hline & 2 & 221 & 522.48 & 120.1625 & $144.1190^{* * *}$ \\
\hline & 3 & 221 & 717.24 & 611.1093 & \\
\hline
\end{tabular}

${ }^{\text {NS Non significant, }}{ }^{*} p<.05,{ }^{* *} p<.01,{ }^{* * *} p<.001$, or ${ }^{+} p<.10$.

Table 3. Variable importance of low-income children

\begin{tabular}{c|c}
\hline reactivity & 1.058300 \\
mature & 1.858829 \\
emotional & 3.210256 \\
learning & 2.522004 \\
reinforcement & 3.496940 \\
community & 2.786381 \\
bond & 1.082549 \\
spatial & 2.580411 \\
estate & 5.818619 \\
asset & 4.166730 \\
income & 4.668745 \\
\hline
\end{tabular}

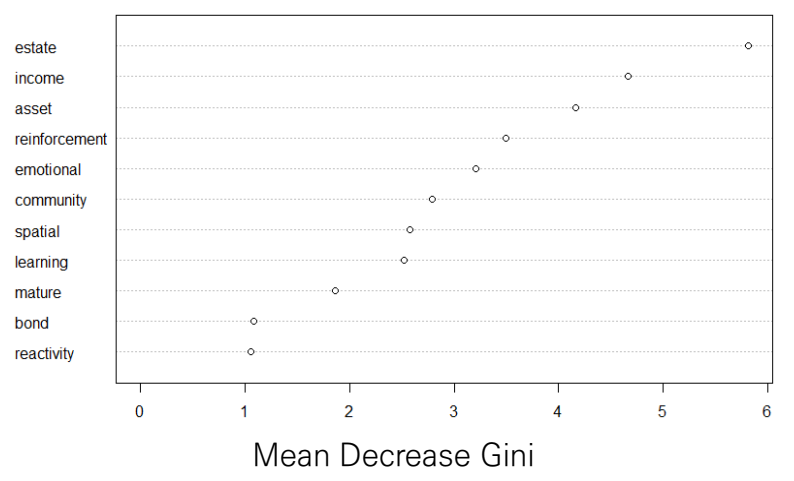

Fig. 1. Variable importance of low-income children. 
Table 4. Variable importance of middle-income children

\begin{tabular}{c|c}
\hline reactivity & 2.013134 \\
mature & 1.867608 \\
emotional & 7.891377 \\
learning & 4.439860 \\
reinforcement & 5.528867 \\
community & 3.783405 \\
bond & 1.211388 \\
spatial & 2.286592 \\
estate & 7.017216 \\
asset & 6.550320 \\
income & 5.052880 \\
\hline
\end{tabular}

Table 5. Variable importance of high-income children

\begin{tabular}{c|c}
\hline reactivity & 1.775523 \\
mature & 1.732404 \\
emotional & 2.656131 \\
learning & 3.158578 \\
reinforcement & 2.981515 \\
community & 2.093813 \\
bond & 1.056499 \\
spatial & 1.646225 \\
estate & 5.896496 \\
asset & 4.832238 \\
income & 4.836504 \\
\hline
\end{tabular}

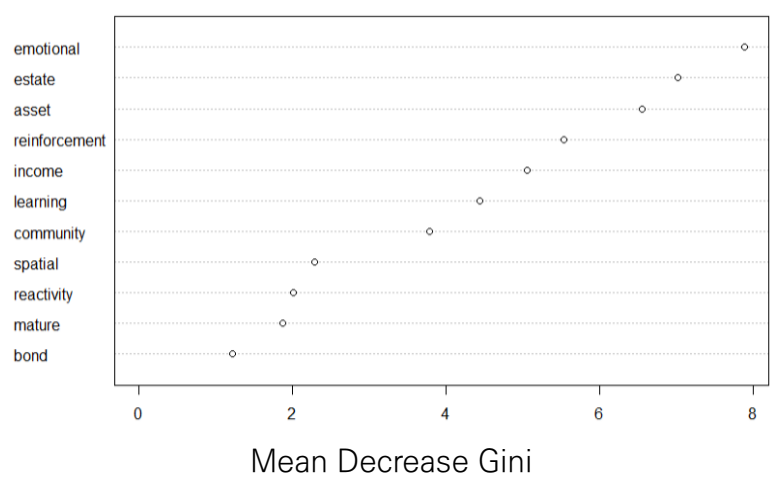

Fig. 2. Variable importance of middle-income children.

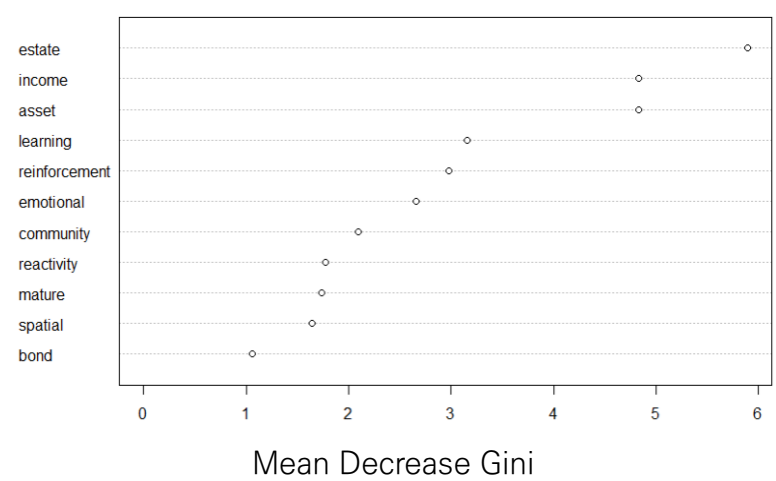

Fig. 3. Variable importance of high-income children.

Table 6. SVM on the prediction of organizational planning executive functions for children by income level

\begin{tabular}{cccccccccc}
\hline & & Low-income & \multicolumn{3}{c}{ Middle-income } & \multicolumn{3}{c}{ High-income } \\
\hline exf & 1 & 2 & 3 & 1 & 2 & 3 & 1 & 2 & 3 \\
1 & 84 & 0 & 1 & 76 & 1 & 0 & 101 & 12 & 6 \\
2 & 0 & 65 & 1 & 0 & 58 & 0 & 0 & 42 & 2 \\
3 & 0 & 1 & 60 & 2 & 0 & 72 & 0 & 1 & 43 \\
\hline kappa & & 0.9785613 & & & 0.9783232 & & & 0.8338684 & \\
\hline
\end{tabular}

learning, reinforcement, and emotional.

\section{SVM analysis on prediction of children's planning-organizing executive functions by income level}

Table 6 shows the results of analyzing classification and prediction of children's planning-organizing executive functions by income level with family wealth and home environment factors. Considering that the result is accurate when kappa, which is the accuracy in classification and prediction, is .6 or higher (Na, 2017), all three groups turned out to have high accuracy in classification and prediction. High planning-organizing executive function was marked as 1 , medium as 2 , and low as 3 . The high-income group had most children with high planning-organizing function, followed by low-income and middle income.

\section{Conclusion}

This study analyzed the importance of variables involved in classification and prediction and the classification predictive model of planning-organizing executive functions 
using children's home environment quality and wealth factors by income group. The results of analysis using the 10th Panel Study on Korean Children data are as follows.

First, as a result of comparing the variables by income group, there was a significant difference in children's planning-organizing executive functions, mature, emotional, learning, reinforcement, community, spatial, estate, asset, and income. This indicates that development of children's planning-organizing executive functions varies among income groups due to specific factors of family wealth and home environment, thereby requiring different approaches.

Second, RF was used to analyze the importance of variables related to classification and prediction of home environment quality and wealth factors in children's planning-organizing executive functions by income group. The importance is represented by MDG calculated by removing prediction impurities by variables used. The top three variables in importance were estate, income, and asset for both high-income and low-income groups, while emotional was the most important variable for the middle-income group, followed by estate and asset. In all three groups, wealth factors had a great impact on classification and prediction of children's planning-organizing executive functions, especially estate. This implies that it is necessary to expand the scope of parents' capital from the conventional method that had focused on income as parents' investment in their children (Kim et al., 2020). Moreover, estate income that is classified as surplus capital led to overinvestment in children's education, which intensifies the education gap and serves as an unearned income passed down among generations, thereby causing inequality and inheritance of social class. This implies that social inequality changes even the executive functions, putting children living in poverty in an even more disadvantaged biological environment, which may affect the entire life of the children.

The top three predictor variables of children's planning-organizing executive functions were the same in high-income and low-income groups, but while estate, income, and asset in the high-income group indicated investment and support in terms of advantage, those variables in the low-income group indicated negligence in investment in terms of disadvantage. Considering that estate, asset, and income of the low-income group are significantly lower than the high-income group, the order of importance in wealth factors for planning-organizing executive functions of children from low-income families reflects their disadvantages in classification and prediction (Bush et al., 2000). Meanwhile, unlike low-income and high-income groups, children from middle-income families showed the highest score in emotional. This indicates that the strong power of wealth can be put on the back burner of home environment factors like emotional in middle-income groups. In other words, when the income is too much or too little in a group that is extremely affected by income, home environment created by family members has little effect on classification and prediction and formation of children's planning-organizing executive functions, whereas wealth factors have powerful effect. If certain income is guaranteed, environmental factors such as home environment have more effect on development of children's intellectual skills than wealth factors (Kim et al., 2000). In child development, home environment quality and wealth are known to have a dominant influence (Lawson et al., 2017; Kim and Pak, 2018), but which of the two had more influence had been unclear in the past, but this study proved the order of importance between home environment quality and wealth by income group.

Third, as a result of SVM analysis, it was found that home environment quality and wealth factors showed high accuracy in classification and prediction of children's planning-organizing executive functions. This indicates that only home environment quality and wealth factors can be accurate, and at the same time, the variables in this study can have strong classification and prediction power even when income levels are divided. Moreover, children's planning-organizing executive functions vary among income groups. This is consistent with the results of previous studies that children's development is related to the economic situation of the family (Brooks-Gunn and Duncan, 1997; Mayer, 2002; Eamon, 2002; Kim and Lee, 2007; Lawson et al., 2017; Kim and Pak, 2018) and home environment quality (Son and Morrison, 2010; Kiss et al., 2014; Bae and Kim, 2018), but this study is different from others as it empirically reviewed the fact that children's planning-organizing executive functions, which had been considered inherent human traits, are also classified and predicted differently depending on the income group. The de- 
velopment level of planning-organizing executive functions by income group in terms of quantity showed that the high-income group had the biggest number of children classified and predicted at a high level, followed by the low-income and middle-income groups. The middle-income group showed the biggest number of children at a low level, followed by the low-income and high-income groups. One thing to note is that, in the case of children from middle-income families, there were few high-level planning-organizing executive function and low-level planning-organizing executive function compared to low-income or high-income groups. This indicates that the relationship between wealth factors and children's planning-organizing executive functions was nonlinear, showing a difference from studies proving that low socioeconomic status of the family consistently leads to low executive functions (St. John et al., 2019). This result implies that national intervention can offset the risk of poverty to a certain extent in the development of children from the low-income group and raises the need to inspect the development environment of children from the middle-income group as well.

The high-income group is developing children's intellectual skills in a more advantageous condition where they can use educational resources through wealth factors, and the low-income receives help from the government due to their disadvantages in wealth factors. However, the middle-income group can neither sufficiently use wealth factors for development of intellectual skills nor receive enough help from the government compared to the low-income group, which may put them in a more disadvantageous position than the low-income group in terms of child development. Therefore, it is necessary to come up with a plan to provide an emotional environment, which showed the highest importance in the middle-income group. Once a certain level of income is guaranteed, the emotional environment provided by the family directly leads to children's intellectual skills, which must be also considered in developing support measures for development of children from low-income families as well. Considering the possibility of downgrading such as destruction of the middle-income group due to intense polarization in Korea, it is necessary to consider that the specificity in classification and prediction of children's planning-organizing executive func- tions from the middle-income group may also be the specificity in the low-income group as well.

Children's planning-organizing executive functions have significance in that they have a direct and indirect effect on life in adulthood beyond just one stage. Since it has been proved that vulnerability in home environment quality and economic factors in development of these intellectual skills leads to vulnerability of the child from the beginning, there is an urgent need for multidimensional social intervention from an integrated perspective for children to get a fair start. Moreover, it is necessary to set policy goals with more subdivided subjects in creating an environment for child development.

The limitations of this study and suggestions for further research are as follows.

First, by analyzing mediating or moderating variables to classify and predict children's executive function such as estate that is analyzed as the most important variable of this study, it will be possible to effectively support the disadvantages in the development of children living in poverty. This is because estate itself is not a dynamic variable that interferes with human development. To this end, it is necessary to include physical elements of housing and community that are macroscopic factors and analyze how estate mediates the physical elements of housing and community.

Second, it is necessary to analyze the longitudinal correlation with the environment that is closest to the development of comprehensive executive functions of children including planning-organizing executive functions. Planningorganizing executive functions are intellectual skills, and it is a well-known fact that the development gap of intellectual skills leads to education gap. However, it is possible to design a fair human development environment by studying which environmental factors are closest to the development of human executive functions and whether these factors are fairly distributed.

\section{References}

Bae, J.H. and J.H. Kim. 2018. The effects of the quality of the home environment and parental mathematical interaction on the cognitive ability of 3-year-olds. Korean 
J Human Dev. 25(1):61-77. http://doi.org/10.15284/kjhd. 2018.25.1.61

Barkley, R.A. 1997. Behavioral inhibition, sustained attention, and executive functions: constructing a unifying theory of ADHD. Psychol. Bull. 121(1):65-94. https:// doi.org/10.1037/0033-2909.121.1.65

Blair, C. and R.P. Razza. 2007. Relating effortful control, executive function, and false belief understanding to emerging math and literacy ability in kindergarten. Child Dev. 78(2):647-663. https://doi.org/10.1111/j.1467-8624. 2007.01019.x

Brito, N.H. and K.G. Noble. 2014. Socioeconomic status and structural brain development. Front. Neurosci. 8: 1-12. http://dx.doi.org/10.3389/fnins.2014.00276

Brooks-Gunn, J. and G.J. Duncan. 1997. The effects of poverty on children. Future Child. 7(2):55-71. https://doi. org/10.2307/1602387

Bush, G., P. Luu, and M.I. Posner. 2000. Cognitive and emotional influences in anterior cingulate cortex. Trends Cogn. Sci. 4(6):215-222. https://doi.org/10.1016/S13646613(00)01483-2

Carlson, S.M., L.J. Moses, and L.J. Claxton. 2004. Individual differences in executive functioning and theory of mind: An investigation of inhibitory control and planning ability. J. Exp. Child Psychol. 87(4):299-319. https://doi. org/10.1016/j.jecp.2004.01.002

Choi, P.S. and I.S. Min. 2018. A predictive model for the employment of college graduates using a machine learning approach. J. Vocat. Edu. Train. 21(1):31-54. http:// doi.org/10.36907/krivet.2018.21.1.31

Diamond, A. 2013. Executive functions. Annu. Rev. Psychol. 64:135-168. https://doi.org/10.1146/annurev-psych-113011 $-143750$

Diamond, A. and D.S. Ling. 2016. Conclusions about interventions, programs, and approaches for improving executive functions that appear justified and those that, despite much hype, do not. Dev. Cogn. Neurosci. 18:3448. https://doi.org/10.1016/j.den.2015.11.005

Duncan, R.J., M.M. McClelland, and A.C. Acock. 2017. Relations between executive function, behavioral regulation, and achievement: moderation by family income. J. Appl. Dev. Psychol. 49:21-30. https://doi.org/10. 1016/j.appdev.2017.01.004

Eamon, M.K. 2002. Effects of poverty on mathematics and reading achievement of young adolescents. J. Early Adolesc. 22(1):49-74. https://doi.org/10.1177/02724316 02022001003

Espy, K.A., M.M. McDiarmid, M.F. Cwik, M.M. Stalets, A. Hamby, and T.E. Senn. 2004. The contribution of executive functions to emergent mathematic skills in preschool children. Dev. Neuropsychol. 26(1):465-486. https://doi.org/10.1207/s15326942dn2601_6

Evans, G.W. and P. Kim. 2007. Childhood poverty and health: Cumulative risk exposure and stress dysregulation. Psychol. Sci. 18(11):953-957. https://doi.org/10.1111/j. 1467-9280.2007.02008.x.

Evans, G.W. and P. Kim. 2012. Childhood poverty, chronic stress, self-regulation, and coping. Child Dev. Perspect. 7(1):43-48. https://doi.org/10.1111/cdep.12013

Gassman-Pines, A. and H. Yoshikawa. 2006. The effects of antipoverty programs on children's cumulative level of poverty-related risk. Dev. Psychol. 42(6):981-999. https://doi.org/10.1037/0012-1649.42.6.981

Gershoff, E.T., J.L. Aber, C.C. Raver, and M.C. Lennon. 2007. Income is not enough: incorporating material hardship into models of income associations with parenting and child development. Child Dev. 78(1):70-95. https://doi.org/10.1111/j.1467-8624.2007.00986.x

Graziano, P.A., R.D. Reavis, S.P. Keane, and S.D. Calkins. 2007. The role of emotion regulation in children's early academic success. J. Sch. Psychol. 45(1):3-19. https:// dx.doi.org/10.1016/j.jsp.2006.09.002

Jang, H.S. and K.H. Kim. 2014. The effect of poverty on children's development : Role of cumulative risk factors. J. Korean Soc. Child Welf. 47:185-216.

Kim, H.J. and B.H. Lee. 2007. Effects of family background, social capital and cultural capital on the children's academic performance. Korean J. Popul. Stud. 30(1):125-148.

Kim, H.O. and H.S. Pak. 2018. Moderating effects of community factors on caregiver-family factors affecting behavior problems of poor children. Korean J. Child Educ. 27(3):31-54. http://dx.doi.org/10.17643/KJCE.2018.27.3.02

Kim, H.O., J.S Ryu, and Y.J. Song. 2020. Predictive analysis of children's intellectual functions in relation to family wealth and community factors. J. Korean Soc. Child Welf. 69(4):1-29. http://doi.org/10.24300/jkscw.2020.12. 69.4.1 
Kishiyama, M.M., W.T. Boyce, A.M. Jimenez, L.M. Perry, and R.T. Knight. 2009. Socioeconomic disparities affect prefrontal function in children. J. Cogn. Neurosci. 21(6):1106-1115. https://doi.org/10.1162/jocn.2009.21101

Kiss, M., G. Fechete. M. Pop, and G. Susa. 2014. Early childhood self-regulation in context: parental and familial environmental influences. Cog. Brain Behavr. 18(1): $55-85$.

Kuhl, P.K. 2007. Is speech learning "gated" by the social brain? Dev Sci. 10(1):110-120. https://doi.org/10.1111/ j.1467-7687.2007.00572.x

Lawson, G.M., C.J. Hook, and M.J. Farah. 2017. A metaanalysis of the relationship between socioeconomic status and executive function performance among children. Dev Sci. 21(2):1-22. https://doi.org/10.1111/desc.12529

Lee, J.Y. and K.A. Lee. 2004. Individual and familial factors in relation to school adjustment of elementary school students. Korean J. Couns. Psychother. 16(2): 261-276.

Lee, S.S., B.K. Yoo, Y.T. Kim, and H.S. Kim. 2007. Functions of orbitofrontal cortex. J. Korean Soc. Biol. Ther. Psychiatry 13(1):36-44.

Lee, W.J., H.J. Kwon, and S.E. Yang. 2009. Child poverty. Korean J. Child Stud. 30(6):337-347.

Marcineková. T., D. Borbélyová, and A. Tirpáková. 2020. Optimization of children's transition from preschool and family environment to the first grade of primary school in Slovakia by implementation of an adaptation programme. Child. Youth Serv. Rev. 119:105483. https:// doi.org/10.1016/j.childyouth.2020.105483

Mayer, S.E. 2002. The influence of parental income on children's outcomes. Knowledge management group, Ministry of Social Development, Te Manatu Whakahiato Ora. Retrieved from https://www.researchgate.net/publication/239574341

Meltzer, L. 2007. Executive function in education: from theory to practice. New York, NY: Guilford.

Miyake, A., N.P. Friedman, M.J. Emerson, A.H. Witzki, A. Howerter, and T.D. Wager. 2000. The unity and diversity of executive functions and their contributions to complex "frontal lobe" tasks: A latent variable analysis. Cogn. Psychol. 41(1):49-100. https://doi.org/10.1006/ cogp.1999.0734

Na, J.H. 2017. R Data Mining. Paju, Korea: Freeacademy. Noble, K.G., M.F. Norman, and M.J. Farah. 2005.
Neurocognitive correlates of socioeconomic status in kindergarten children. Dev. Sci. 8(1):74-87. https://doi.org/10.1111/j.1467-7687.2005.00394.X

Noble, K.G., S.M. Houston, E. Kan, and E.R Sowell. 2012. Neural correlates of socioeconomic status in the developing human brain. Dev. Sci. 15(4):516-527. https://doi.org/10.1111/j.1467-7687.2012.01147.x

Noble, K.G., S.M. Houston, N.H Brito, H. Bartsch, E. Kan, J.M. Kuperman, N. Akshoomoff, D.G. Amaral, C.S. Bloss, O. Libiger, N.J. Schork, S.S. Murray, B.J. Casey, L. Chang, T.M. Ernst, J.A. Frazier, J.R. Gruen, D.N. Kennedy, P. Van Zijl, S. Mostofsky, W.E. Kaufmann, T. Kenet, A.M. Dale, T.L. Jernigan, and E.R. Sowell. 2015. Family income, parental education and brain structure in children and adolescents. Nat. Neurosci. 18(5):773-778. https://doi.org/10.1038/nn.3983

Organisation for Economic Co-operation and Development (OECD). 2018. June 15. A broken social elevator? how to promote social mobility. Retrieved from https://www. oecd.org/social/broken-elevator-how-to-promote-socialmobility-9789264301085-en.htm

Poland, S.E., C.P. Monks, and S. Tsermentseli. 2016. Cool and hot executive function as predictors of aggression in early childhood: Differentiating between the function and form of aggression. Br. J. Dev. Psychol. 34(2): 181-197. https://doi.org/10.1111/bjdp.12122

Sohn, B., A. Buchanan, K.H. Heo, and J.J. Lee. 2019. Explanatory effects of young childhood caregiving environment, child's pro-social behavior, and child self-regulation skills on adolescent problem behavior. Child. Youth Serv. Rev. 100:298-303. https://psycnet.apa.org/ doi/10.1016/j.childyouth.2019.03.016

Son, S.H. and F.J. Morrison. 2010. The nature and impact of changes in home learning environment on development of language and academic skills in preschool children. Dev. Psychol. 46(5):1103-1118. https://doi. org/10.1037/a0020065

Song, H.J. 2011. Executive function and school adjustment in elementary school students. J. Korean Assoc. Psychother. 3(2):31-39.

Song, H.J. 2014. Validity of child-adolescent self-reported executive function difficulty screening questionnaire. Korean J. Clin. Psychol. 33(1):121-137. https://doi. org/10.15842/kjcp.2014.33.1.008

St. John, A.M., M. Kibbe, and A.R. Tarullo. 2019. A sys- 
tematic assessment of socioeconomic status and executive functioning in early childhood. J. Exp. Child. Psychol. 178:352-368. https://doi.org/10.1016/j.jecp.2018. 09.003

Tesser, A., R. Forehand, G. Brody, and N. Long. 1989. Conflict: the role of calm and angry parent-child discussion in adolescent adjustment. J. Soc. Clin. Psychol. 8(3):317-330. https://doi.org/10.1521/jscp.1989.8.3.317

Torgesen, J.K. 1994. Issues in the assessment of executive function: An information-processing perspective. In G. R. Lyon (Ed.), Frames of reference for the assessment of learning disabilities: New views on measurement issues (pp. 143-162). Baltimore, MD: Paul H. Brooks Publishing Co. Retrieved from https://psycnet.apa.org/ record/1994-97166-007

Welsh, M.C. and M. Huizinga. 2005. Tower of Hanoi disk-transfer task: Influences of strategy knowledge and learning on performance. Learn. Individ. Differ. 15(4):
283-298. https://doi.org/10.1016/j.lindif.2005.05.002

Xiaoli, N., L. Xiaoran, and W. Yuping. 2021. The impact of family environment on the life satisfaction among young adults with personality as a mediator. Child. Youth Serv. Rev. 120:105653. http://dx.doi.org/10.1016/ j.childyouth.2020.105653

Yeon, E.M. and H.S. Choi. 2019. Exploring the latent classes in students' executive function difficulty by mother and teacher: Multivariate analysis across school adaption and academic performance. J. Korea Acad. Ind. Coop. Soc. 20(6):38-47. https://doi.org/10.5762/KAIS. 2019.20.6.38

Yi, Y.J. and E.O. Jun. 2019. Exploring variables affecting school adjustment in first grade elementary students: Focused on mother's employment, home environment, and children's executive function difficulty. Korean J. Child Care Educ. Policy. 13(1):101-121. 